\title{
Psychometric Properties of the Greek Haem-A-QoL for Measuring Quality of Life in Greek Haemophilia Patients
}

\author{
Agoritsa Varaklioti, ${ }^{1,2}$ Nick Kontodimopoulos, ${ }^{2}$ Olga Katsarou, ${ }^{1}$ and Dimitris Niakas ${ }^{2}$ \\ ${ }^{1}$ Blood Center and National Centre for Congenital Bleeding Disorders, Laiko General Hospital, Ag. Thoma 17, 11527 Athens, Greece \\ ${ }^{2}$ Hellenic Open University, Parodos Aristotelous 18, 26335 Patra, Greece \\ Correspondence should be addressed to Agoritsa Varaklioti; rvaraklioti@hotmail.com
}

Received 13 February 2014; Accepted 1 April 2014; Published 6 May 2014

Academic Editor: Panagiotis Tsirigotis

Copyright (c) 2014 Agoritsa Varaklioti et al. This is an open access article distributed under the Creative Commons Attribution License, which permits unrestricted use, distribution, and reproduction in any medium, provided the original work is properly cited.

\begin{abstract}
Background and Objectives. Health Related Quality of Life (HRQoL) is an important health outcome measure in haemophilia. The aim of this study was to assess the psychometric properties of the Greek version of Haem-A-QoL, a disease-specific questionnaire for haemophiliacs. Methods. Haem-A-QoL and SF-36 were administered to 118 adult haemophilia patients. Hypothesized scale structure, internal consistency (Cronbach's $\alpha$ ), and test-retest reliability, as well as various types of construct validity were evaluated. Results. Scale structure of Haem-A-QoL was confirmed, with good item convergence (87\%) and discrimination (80.6\%) rates. Cronbach's $\alpha$ was $>0.70$ for all but one dimension (dealing) and test-retest reliability was significantly high. The strength of Spearman's correlations between Haem-A-QoL and SF-36 scales ranged from 0.25 to $0.75(P<0.01)$. Multiple stepwise linear regression analysis revealed that all but one Haem-A-QoL dimensions were important predictors of SF-36 scales. Known-groups comparisons yielded consistent support of the instruments' construct validity and significant relationships were identified for age, educational level, haemophilia type, disease severity, and viral infections. Conclusion. Overall, the psychometric properties of the Greek version of Haem-A-QoL, resulting from this first time administration of the instrument to Greek adult haemophiliacs, confirmed it as a reliable and valid questionnaire for assessing haemophilia-specific HRQoL in Greece.
\end{abstract}

\section{Introduction}

Haemophilia is a rare congenital bleeding disorder, characterized by posttraumatic and spontaneous bleeds, mainly in joints and muscles, leading to joint degradation, painful arthritis, and arthropathy. Deficiency of coagulation factors VIII and IX accounts for haemophilia A and haemophilia $B$, respectively. Severity of the disease is associated with the quantity levels of factors VIII and IX in the patients' plasma; haemophilia is described as severe, moderate, and mild, when the residual plasma activity of the clotting factor is $<1 \%$, between $1 \%$ and $5 \%$, and between $5 \%$ and $40 \%$, respectively [1-3]. Both haemophilia A and haemophilia B are X-linked genetic disorders and therefore occur almost exclusively in males. It is estimated that the number of haemophilia patients worldwide is approximately 400,000. In Greece 912 patients are estimated to suffer from haemophilia A or B, 716 of which are adult patients [4].
Standard treatment is based on the intravenous replacement therapy with concentrates of coagulation factors either when bleeding occurs (on demand therapy) or preventively [1]. Traditional outcome measures of haemophilia care are restricted to clinical outcomes, such as arthropathyassociated pain, number of joint bleeds, and loss of motion range.

Health-related quality of life (HRQoL) is increasingly recognized as a significant component of modern haemophilia management and as an important health outcome measure in haemophilia, which may help in improving treatment strategies. Several studies in the literature assess HRQoL in haemophilia adult patients, using mainly generic instruments, like SF-36, SF-12, and EQ-5D [5-7]. Lately, a few disease-specific questionnaires for haemophilia patients have been developed and validated. These include Haemo-QoL, CHO-KLAT, and QoL questionnaire for Young patients, which were designed for children [8-11], while Hemo-QoL-A, 
Hemophilia-QoL, Hemolatin-QoL, and Haem-A-QoL apply to adult patients [12-17]. The latter was developed and pilottested using patient-based focus groups $(n=32)$ and expert groups organized with physicians and nurses initially [18]. It was validated in 233 Italian adult haemophilia patients [19] and has been linguistically validated in more than 30 languages, including Greek [20, 21].

The aim of the present study was the validation of the Greek version of Haem-A-QoL, a disease-specific questionnaire, and the evaluation of its psychometric properties, with regard to reliability (internal consistency and test-retest) and construct validity. To the best of our knowledge, this is the first study in Greek adult haemophilia patients with a diseasespecific instrument. This validated Greek version of HaemA-QoL questionnaire can be subsequently utilized in future studies monitoring HRQoL in adult haemophilia patients in Greece.

\section{Methods}

2.1. Instruments. Haem-A-QoL was designed for adult patients with haemophilia. It consists of 46 items comprising 10 dimensions ("physical health," "feelings," "view," "sport and leisure time," "work and school," "dealing," "treatment," "future," "family planning," and "relationships/partners") and a scale representing total score $[15,18,22,23]$. Scoring is performed by transforming the scores achieved in each dimension, as well as the total score, on scales ranging from 0 to 100 , with 0 representing the best and 100 the worst HRQoL [24]. The Greek version of the Haem-A-QoL questionnaire was used in this study with the expressed permission of the Haemo-QoL group.

The Short Form Health Survey (SF-36) is a self-administered generic HRQoL questionnaire for adults [25], allowing the comparison of a specific disease such as haemophilia with norm data of the general population related to gender and age groups. It consists of 36 items pertaining to eight dimensions of HRQoL (PF: physical functioning; RF: role physical; BP: bodily pain; GH: general health perception; VT: vitality; SF: social functioning; RE: role emotional functioning; and $\mathrm{MH}$ : mental health). Each of the eight domains can be transformed into scores ranging from 0 (worst quality of life) to 100 (best quality of life); two summary scores can be calculated, for physical component score (PCS) and mental component score (MCS), respectively. The SF-36 has been translated, psychometrically tested, and normed in over 30 countries and is available in most European languages. The validated Greek version [26] of the generic SF-36 Health Survey was used as the "gold standard" for HRQoL assessment in this study.

2.2. Patients and Data Collection. The study was conducted in the National Centre for Congenital Bleeding Disorders in Laiko General Hospital of Athens. The Hospital's Review Board granted ethical approval. The data were collected between September 2011 and March 2012 and the sample consisted of adult patients with haemophilia A and haemophilia B. The survey included the SF-36 and the Greek version of the Haem-A-QoL questionnaires as well as sociodemographic questions, which were administered for self-completion.
All the necessary clinical data were obtained from the patients' medical records. Completion time was approximately $30 \mathrm{~min}$, and 118 out of 122 visiting the facility during the study period agreed to participate ( $96.72 \%$ response rate). During the study period, 30 patients returned within 15 days after their initial visit and were asked to complete the two questionnaires again. 23 out of 30 agreed and the response rate of repeatedly completed questionnaires was $76.7 \%$.

2.3. Data Analysis. Percentages of ceiling and floor scores were calculated as an indication of the instrument ability to detect changes over time. Scale internal consistency reliability was assessed using Cronbach's $\alpha$ and the 0.70 standard for group-level comparisons was adopted [27]. Test-retest reliability was assessed using the correlation coefficient over a period of about 2 weeks. Item-internal consistency, which is substantial when correlation between an item and its hypothesized scale (corrected for overlap) is $>0.40$, and item discriminant validity, which is successful when correlation between an item and its own scale is significantly higher $(>2$ standard errors) than with other scales, were used to examine the hypothesized scale structure.

Spearman's correlations between Haem-A-QoL and SF36 scales were used to assess convergent construct validity. Based on the literature, scales measuring similar HRQoL dimensions were hypothesized to be strongly correlated $(>0.50)$ [28]. Construct validity was also examined using the interscale correlations between Haem-A-QoL and SF36 , conceptually related scales would substantially correlate $(>0.40)$ and scales with less in common would show lower correlations. Each SF-36 scale was separately regressed against the Haem-A-QoL dimensions in order to identify aspects of the disease-specific instrument more closely linked to general HRQoL [29]. Known-groups' validity was assessed by testing Haem-A-QoL's ability to discriminate between groups of patients known to differ by sociodemographic and clinical characteristics. Age group, educational level, employment, and family status, as well as several clinical characteristics were used as testing criteria and differences were examined with $t$-test and ANOVA, Kruskal Wallis, and Mann Whitney tests. Multivariate OLS regression analysis identified independent sociodemographic, clinical, and treatment-related variables that affect HRQoL. All analyses were performed using SPSS software, version 19.0 (SPSS Inc, Chicago IL).

\section{Results}

The sociodemographic and clinical characteristics of the participating patients are shown in Table 1. The patients' age ranged between 18 and 75 years old, with a median age of 39 and mean age $39.6( \pm 12.9)$. Haemophilia is an X-linked genetic disease; therefore the majority of the patient sample was men $(99.2 \%)$. The only woman in the sample, who was a carrier of the haemophilia gene, had low levels of factor VIII and similar to mild haemophilia patient symptoms. The majority of the patients were single (61\%), worked as employees (32.2\%), had graduated from high school (57.6\%), 
TABLE 1: Sociodemographic and clinical characteristics of the sample $(n=118)$.

(a)

\begin{tabular}{|c|c|c|}
\hline Sociodemographic Data & $n$ & $\%$ \\
\hline \multicolumn{3}{|l|}{ Age group } \\
\hline $18-30$ yrs & 33 & 28.0 \\
\hline $31-40 \mathrm{yrs}$ & 31 & 26.3 \\
\hline $41-50$ yrs & 30 & 25.4 \\
\hline $51-60 \mathrm{yrs}$ & 16 & 13.6 \\
\hline$>60 \mathrm{yrs}$ & 8 & 6.8 \\
\hline \multicolumn{3}{|l|}{ Gender } \\
\hline Male & 117 & 99.2 \\
\hline Female & 1 & 0.8 \\
\hline \multicolumn{3}{|l|}{ Family status } \\
\hline Unmarried & 72 & 61.0 \\
\hline Married & 43 & 36.4 \\
\hline Divorced/widowed/separated & 3 & 2.6 \\
\hline \multicolumn{3}{|l|}{ Residence } \\
\hline Attica & 68 & 57.6 \\
\hline Rest of Greece & 50 & 42.4 \\
\hline \multicolumn{3}{|l|}{ Educational level } \\
\hline Elementary & 6 & 5.1 \\
\hline High school & 68 & 57.6 \\
\hline Graduate & 40 & 33.9 \\
\hline Postgraduate & 4 & 3.4 \\
\hline \multicolumn{3}{|l|}{ Employment } \\
\hline Unemployed & 18 & 15.3 \\
\hline Employee & 38 & 32.2 \\
\hline pensioner & 32 & 27.1 \\
\hline Student & 18 & 15.3 \\
\hline Farmer & 4 & 3.4 \\
\hline Self-employed & 8 & 6.8 \\
\hline
\end{tabular}

(b)

\begin{tabular}{lcc}
\hline Clinical data & $n$ & $\%$ \\
\hline Haemophilia & & \\
A (factor VIII deficiency) & 92 & $\mathbf{7 8 . 0}$ \\
B (factor IX deficiency) & 26 & 22.0 \\
Severity & & \\
$\quad$ Severe & 75 & $\mathbf{6 3 . 6}$ \\
Moderate & 16 & 13.5 \\
Mild & 27 & 22.9 \\
Inhibitor & & \\
Yes & 9 & 7.6 \\
No & 109 & $\mathbf{9 2 . 4}$ \\
Prophylaxis & & \\
No & 90 & $\mathbf{7 6 . 3}$ \\
Transient & 11 & 9.3 \\
Constant & 17 & 14.4 \\
Haemarthrosis & & $\mathbf{7 8 . 0}$ \\
Yes & 92 & 22.0 \\
No & 26 & \\
\hline
\end{tabular}

(b) Continued.

\begin{tabular}{|c|c|c|}
\hline Clinical data & $n$ & $\%$ \\
\hline \multicolumn{3}{|l|}{ Muscle hematomas } \\
\hline Yes & 106 & 89.8 \\
\hline No & 12 & 10.2 \\
\hline \multicolumn{3}{|l|}{ Other bleeding } \\
\hline Yes & 88 & 74.6 \\
\hline No & 30 & 25.4 \\
\hline \multicolumn{3}{|l|}{ Factor concentrates } \\
\hline Recombinant & 112 & 94.9 \\
\hline Plasma derived & 6 & 5.1 \\
\hline \multicolumn{3}{|l|}{ HIV infection } \\
\hline Yes & 33 & 28.0 \\
\hline No & 85 & 72.0 \\
\hline \multicolumn{3}{|l|}{ HCV infection } \\
\hline Yes & 84 & 71.2 \\
\hline No & 34 & 28.8 \\
\hline \multicolumn{3}{|l|}{ HBV infection } \\
\hline Yes & 2 & 1.7 \\
\hline No & 116 & 98.3 \\
\hline
\end{tabular}

and lived in the greater area of Attica (57.6\%). The predominant form of haemophilia was A (78\%) and $63.6 \%$ of the individuals had severe haemophilia. Most of the patients suffered from hemarthrosis (78.0\%), muscle hematomas (89.8\%), and other types of bleeding (74.6\%). Regarding viral infections, 84 patients $(71.2 \%)$ were $\mathrm{HCV}$ positive and 33 patients $(28.0 \%)$ were HIV positive. Concerning replacement treatment, $14.4 \%$ of the patients received constant and $9.3 \%$ transient prophylaxis and recombinant factor concentrates were administered to $94.9 \%$ of the patients (Table 1 ).

Data on central tendency, variability, and reliability of Haem-A-QoL are depicted in Table 2. No noteworthy floor or ceiling effects were observed in all the dimensions of the Haem-A-QoL instrument. Only one dimension (relationship/partnership) suffered from a marginally high floor effect $(40.7 \%)$. Throughout the instrument, only one scale (dealing) did not meet the 0.70 internal consistency criterion (0.585). Additionally, Haem-A-QoL demonstrated increased test-retest reliability with a significantly high correlation coefficient $(>0.87)$ in all the scales.

Significantly higher item-scale correlations between items and their hypothesized scales than with competing scales were observed (Table 3 ). The 0.40 item-scale correlation criterion was satisfied, confirming item convergence in 40/46 (87.0\%) tests for Haem-A-QoL. Accordingly, item discrimination was successful in $341 / 423$ (80.61\%) of the respective tests. The most obvious scaling failures occurred in the treatment and relationship/partnership scales. 
TABLE 2: Central tendency, variability, and reliability of the Haem-A-QoL scales.

\begin{tabular}{|c|c|c|c|c|c|c|c|c|}
\hline & Number of items & Mean (SD) & $95 \% \mathrm{CI}$ & Median & Floor (\%) & Ceiling (\%) & Cronbach's $\alpha$ & $\begin{array}{l}\text { Test-retest } \\
\text { reliability }\end{array}$ \\
\hline Physical health & 5 & $42.97(23.44)$ & $38.69-47.24$ & 45.00 & $0(7.6)$ & $95(0.8)$ & 0.871 & 0.876 \\
\hline Feelings & 4 & $35.33(23.49)$ & $31.05-39.61$ & 31.25 & $0(12.7)$ & $100(0.8)$ & 0.863 & 0.974 \\
\hline View & 5 & $40.93(20.64)$ & $37.17-44.69$ & 40.00 & $0(0.8)$ & $100(0.8)$ & 0.774 & 0.960 \\
\hline Sports/leisure & 5 & $61.06(21.81)$ & $57.08-65.03$ & 65.00 & $0(1.7)$ & $100(1.7)$ & 0.810 & 0.963 \\
\hline Work/school & 4 & $31.41(19.77)$ & $27.80-35.01$ & 31.25 & $0(11)$ & $81.3(0.8)$ & 0.808 & 0.950 \\
\hline Dealing & 3 & $27.05(19.49)$ & $23.49-30.60$ & 25.00 & $0(9.3)$ & $100(1.7)$ & 0.585 & 0.872 \\
\hline Treatment & 8 & $31.25(17.32)$ & $28.09-34.41$ & 28.12 & $0(0.8)$ & $84.4(0.8)$ & 0.765 & 0.949 \\
\hline Future & 5 & $39.15(20.31)$ & $35.45-42.86$ & 40.00 & $0(2.5)$ & $95(0.8)$ & 0.806 & 0.965 \\
\hline Family planning & 4 & $25.85(23.34)$ & $21.59-30.10$ & 25.00 & $0(15.3)$ & $100(2.5)$ & 0.876 & 0.910 \\
\hline Relationship/partnership & 3 & $24.51(30.14)$ & $19.01-30.00$ & 8.33 & $0(40.7)$ & $100(2.5)$ & 0.954 & 0.981 \\
\hline Total Haem-A-QoL & 46 & $33.59(14.53)$ & $30.94-36.23$ & 33.97 & $4.9(0.8)$ & $71.7(0.8)$ & 0.872 & - \\
\hline
\end{tabular}

SD: standard deviation; 95\% CI: 95\% confidence interval.

TABLE 3: Summary results of scaling assumptions tests.

\begin{tabular}{|c|c|c|c|c|c|}
\hline & \multirow{2}{*}{$N^{*}$} & \multicolumn{2}{|c|}{ Item-internal consistency } & \multicolumn{2}{|c|}{ Item-discriminant validity } \\
\hline & & Range of correlations ${ }^{\dagger}$ & Success/total ${ }^{\ddagger}$ & Range of correlations ${ }^{\S}$ & Success/total ${ }^{9}$ \\
\hline Physical health & 5 & $0.624-0.766$ & $5 / 5$ & $0.08-0.775$ & $37 / 45$ \\
\hline Feelings & 4 & $0.670-0.740$ & $4 / 4$ & $0.03-0.779$ & $28 / 36$ \\
\hline View & 5 & $0.362-0.661$ & $4 / 5$ & $0.12-0.770$ & $40 / 45$ \\
\hline Sports/leisure & 5 & $0.530-0.727$ & $5 / 5$ & $0.01-0.780$ & $38 / 45$ \\
\hline Work/school & 4 & $0.598-0.672$ & $4 / 4$ & $0.06-0.772$ & $31 / 36$ \\
\hline Dealing & 3 & $0.229-0.529$ & $2 / 3$ & $0.49-0.787$ & $27 / 27$ \\
\hline Treatment & 8 & $0.045-0.668$ & $5 / 8$ & $0.04-0.772$ & $62 / 72$ \\
\hline Future & 5 & $0.309-0.758$ & $4 / 5$ & $0.09-0.729$ & $36 / 45$ \\
\hline Family planning & 4 & $0.563-0.827$ & $4 / 4$ & $0.13-0.775$ & $29 / 36$ \\
\hline Relationship/partnership & 3 & $0.897-0.909$ & $3 / 3$ & $0.22-0.797$ & $13 / 36$ \\
\hline
\end{tabular}

${ }^{*}$ Number of questions and number of item-internal consistency tests per dimension.

${ }^{\dagger}$ Range of correlations between questions and their corresponding dimension.

${ }^{\ddagger}$ Number of correlations that are over the acceptable limit of $0.40 /$ total number of correlations.

${ }^{\S}$ Range of correlations between questions and other dimensions.

${ }^{9}$ Number of successful tests of item-discriminant validity/total number of item-discriminant validity tests.

Convergent construct validity was tested by examining conceptually related correlations between the two instruments used, based on findings from the literature. All correlations between generic (SF-36) and disease-targeted (HaemA-QoL) scales, shown in Table 4, were negative, due to the reversed scoring between the two instruments, and strong except for one scale (dealing). Six out of nine hypothesized strong correlations $(>0.50)$ between pairs of Haem-A-QoL and SF-36 scales measuring similar dimensions were confirmed (PF, RP, BP, and PCS of SF-36 with Physical Health of Haem-A-QoL, MH, and MCS of SF-36 with feelings of HaemA-QoL) with correlations ranging from 0.53 to 0.75 and three correlations were borderline (feelings, family planning, and relationship/partnership with $P=0.43,0.47$, and 0.45 , resp.) (Table 4). Noteworthy, strong correlations were observed between almost all dimensions of the Haem-A-QoL with SF36 scales $(P>0.50)$. All hypothesized strong correlations were statistically significant $(P<0.001)$.
Multiple stepwise linear regression analysis identified those Haem-A-QoL dimensions most closely associated with specific domains of HRQoL, as represented by SF-36 scales. In Table 5, only the significant predictors are demonstrated. All Haem-A-QoL dimensions were significantly related to at least SF-36 scale. Only one dimension (dealing) was not a significant predictor of any SF-36 scale. Explanatory power was satisfactory for most models, with the general health $(64.6 \%)$ and bodily pain $(58.3 \%)$ models demonstrating the highest (Table 5).

The ability of the instrument to distinguish between known groups was confirmed with statistically significant correlations between several Haem-A-QoL scales and four sociodemographic variables, that is, age, family status, educational level, and employment, and six disease-specific variables, namely, haemophilia type, disease severity, muscle hematomas, prophylaxis treatment, HCV, and HIV infection (Table 6). 


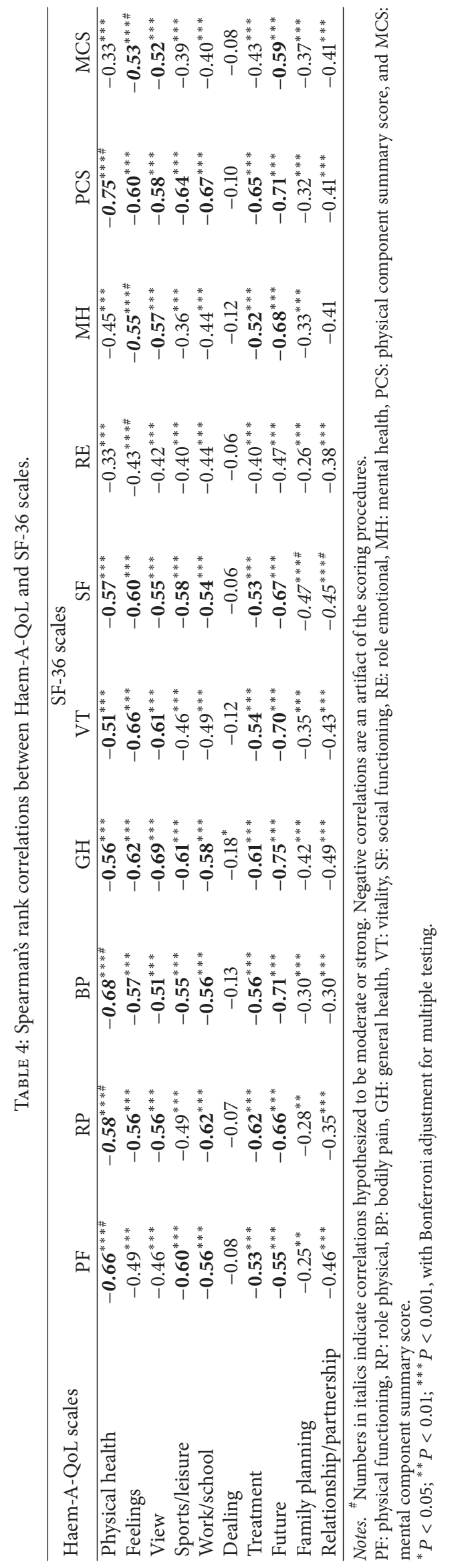


TABLE 5: Multivariate analysis $\left(B\right.$ coefficient $\left.^{(P-\text {-sig. })}\right)$.

\begin{tabular}{|c|c|c|c|c|c|c|c|c|}
\hline \multirow{2}{*}{ Dependent variable predictors } & \multicolumn{8}{|c|}{ Dependent variable } \\
\hline & $\mathrm{PF}$ & $\mathrm{RP}$ & $\mathrm{BP}$ & GH & VT & SF & $\mathrm{RE}$ & MH \\
\hline Physical health & $-0.54^{* * *}$ & - & $-0.41^{* * *}$ & - & - & - & - & - \\
\hline Feelings & - & - & - & - & $-0.51^{* * *}$ & $-0.24^{* *}$ & - & $-0.51^{* *}$ \\
\hline View & - & - & - & $-0.28^{* * *}$ & - & - & - & - \\
\hline Sports/leisure & - & - & - & $-0.25^{* * *}$ & - & $-0.48^{* * *}$ & - & - \\
\hline Work/school & - & $-0.69^{* * *}$ & - & - & - & - & - & - \\
\hline Dealing & - & - & - & - & - & - & - & - \\
\hline Treatment & $-0.31^{*}$ & $-0.70^{* * *}$ & - & - & - & - & - & - \\
\hline Future & - & $-0.66^{* * *}$ & $-0.57^{* * *}$ & $-0.49^{* * *}$ & $-0.32^{* * *}$ & $-0.28^{* *}$ & $-0.713^{* * *}$ & $-0.19^{* * *}$ \\
\hline Family planning & - & $0.30^{*}$ & - & - & $0.14^{*}$ & - & - & - \\
\hline Relationship/partnership & $-0.14^{*}$ & - & - & - & - & - & $-0.302^{* *}$ & - \\
\hline Constant & $102.60^{* * *}$ & $110.25^{* * *}$ & $94.0^{* * *}$ & $91.78^{* * *}$ & $86.37^{* * *}$ & $110.24^{* * *}$ & $102.86^{* * *}$ & $91.58^{* * *}$ \\
\hline Adjusted $R^{2}$ & 0.491 & 0.536 & 0.583 & 0.646 & 0.579 & 0.525 & 0.246 & 0.466 \\
\hline
\end{tabular}

PF: physical functioning, RP: role physical, BP: bodily pain, GH: general health, VT: vitality, SF: social functioning, RE: role emotional, and MH: mental health. ${ }^{*} P<0.05 ;{ }^{* *} P<0.01 ;{ }^{* * *} P<0.001$.

Known-groups validity was confirmed, by comparing mean scale scores across groups known to differ, using sociodemographic and clinical characteristics as the differing criteria. As shown in Table 7, significantly higher scores (lower HRQoL) were observed with increasing age in most of the dimensions (physical health, view, sports/leisure, work/school, treatment, relationships, and total score). Differences were also observed in three dimensions, namely, physical health, work/school and total score, with educational level as the criterion, with more years of education associated with better-reported health (data not shown). Accordingly, higher scores (lower HRQoL) were observed in patients with haemophilia $\mathrm{A}$ in all the Haem-A-QoL dimensions, and in six of them this correlation was also statistically significant. Furthermore, as expected, haemophilia patients with either $\mathrm{HCV}$ or HIV infection presented lower HRQoL, as revealed by the higher scores in all but one (dealing) Haem-A-QoL dimension (Table 7).

The significance of the aforementioned relationships between sociodemographic and clinical variables and HaemA-QoL dimensions was confirmed with multivariate OLS regressions (Table 8 ). In all but three dimensions (feelings, dealing, and treatment), viral infection (HCV or HIV) was identified as a significant predictor of decreased HRQoL, with the regression models explaining between $9 \%$ and $20 \%$ of the variance. Another clinical variable, prophylaxis treatment, was also recognized as a significant predictor of diminished HRQoL in six dimensions, with the models explaining between $3.2 \%$ and $20 \%$ of the variance. Moreover, type of haemophilia was also identified as an important predictor of HRQoL in 5 scales, with the regression models explaining between $3.7 \%$ and $18.1 \%$ of the variance (Table 8 ). Among the sociodemographic variables, age and educational level were the most pronounced predicting factors of reduced perceived health in four and six Haem-A-QoL scales, respectively, and the regression models explaining between 3.3\% and $13.5 \%$ and 3.3 and $18.2 \%$ of the variance (Table 8 ).

\section{Discussion}

The modern management of haemophilia has evidently influenced not only clinical symptoms, that is, orthopedic outcome and survival of patients, but also their perceived HRQoL. Lately, QoL measures have become an indispensable part of clinical trials as one of the most essential patient-rated outcomes (PROs). Similarly, QoL assessment has become also important in pharmacoeconomics $[22,23]$.

Currently, disease-specific questionnaires for assessing patients' HRQoL are increasingly being utilized in routine health monitoring of haemophilia patients. Thus far, there is only one study in Greece measuring HRQoL in haemophilia patients [30]. Nevertheless, in that study, HRQoL of 78 Greek haemophilia patients was assessed using only the generic instruments SF-36 and EQ-5D. Haem-A-QoL is a commonly used disease-specific instrument with very good psychometric characteristics, including good reliability values (Cronbach's $\alpha$ ranging between 0.74 and 0.88 ) and high convergent and discriminant validity $[18,23]$ and it has been translated into more than 30 languages $[20,21]$. Two recent studies, in Turkey and Brazil, use translated versions of these instruments to evaluate health-related quality of life in the corresponding haemophilia populations [31, 32]. However, to the extent of our knowledge, we are unaware of any published validation studies regarding the Greek version of Haem-AQoL. The present study aimed to assess the reliability and validity of the Greek version of the Haem-A-QoL questionnaire and increase confidence in results from future studies in Greece using this instrument in adult haemophiliacs.

The overall results for the psychometric properties of the instrument were quite satisfactory. In general, no floor and ceiling effects were observed, suggesting good discriminative ability and good responsiveness (Table 2 ). The single presence of a marginally high floor effect of one Haem-A-QoL scale (relationship/partnership) does not in the least derogate from the acceptable limits for a satisfactory discriminative ability of the Greek version of this instrument. 


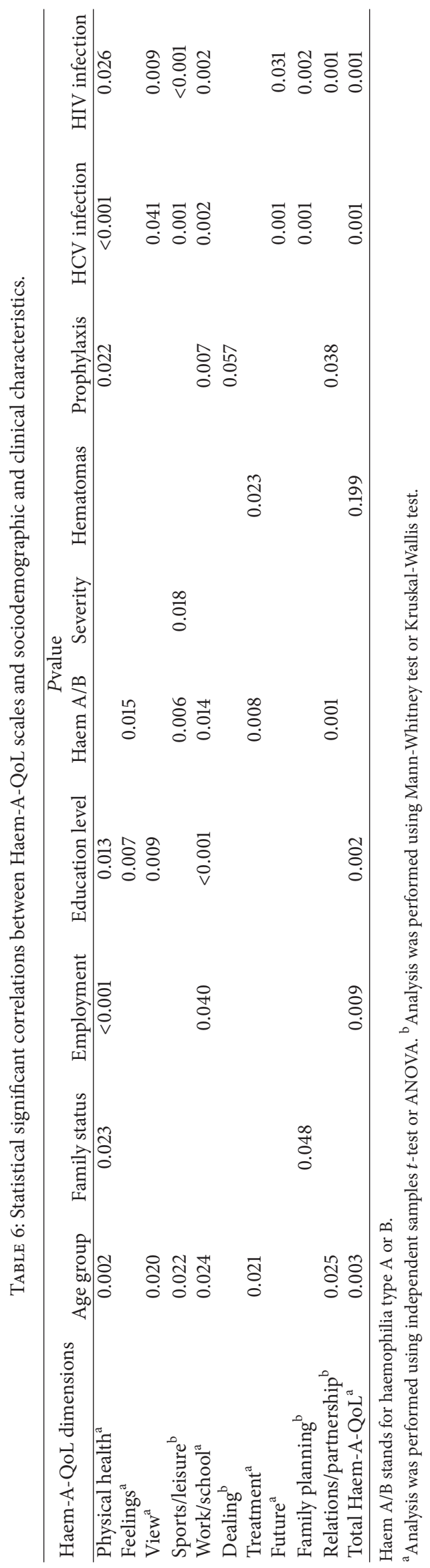


TABLE 7: Stratified Haem-A-QoL scores according to age and health-related characteristics of the sample.

\begin{tabular}{lccccccccccccc}
\hline & $n$ & & $\mathrm{PH}^{\mathrm{a}}$ & $\mathrm{FL}^{\mathrm{a}}$ & $\mathrm{VW}^{\mathrm{a}}$ & $\mathrm{SL}^{\mathrm{b}}$ & $\mathrm{WS}^{\mathrm{a}}$ & $\mathrm{DL}^{\mathrm{b}}$ & $\mathrm{TR}^{\mathrm{a}}$ & $\mathrm{FU}^{\mathrm{a}}$ & $\mathrm{FP}^{\mathrm{b}}$ & $\mathrm{RP}^{\mathrm{b}}$ & $\mathrm{THQ}^{\mathrm{a}}$ \\
\hline Age group & & & & & & & & & & & & \\
18-30 years & 33 & & 30.91 & 29.26 & 33.64 & 52.88 & 23.48 & 21.71 & 25.00 & 31.52 & 17.05 & 13.89 & 26.27 \\
31-40 years & 31 & & 41.13 & 31.65 & 38.06 & 58.39 & 30.65 & 27.15 & 29.23 & 40.32 & 33.06 & 24.19 & 32.84 \\
41-50 years & 30 & & 50.00 & 40.42 & 47.33 & 68.17 & 35.63 & 28.06 & 37.92 & 44.00 & 27.92 & 34.17 & 38.79 \\
51-60 years & 16 & & 51.88 & 39.06 & 42.50 & 66.56 & 34.37 & 31.25 & 31.05 & 42.50 & 30.47 & 27.08 & 35.55 \\
>60 years & 8 & & 55.63 & 47.66 & 55.00 & 67.50 & 45.31 & 36.46 & 40.23 & 41.25 & 17.19 & 28.13 & 41.24 \\
& & $P$ (sig.) & $\mathbf{0 . 0 0 2}$ & 0.139 & $\mathbf{0 . 0 2 0}$ & $\mathbf{0 . 0 2 2}$ & $\mathbf{0 . 0 2 4}$ & 0.533 & $\mathbf{0 . 0 2 1}$ & 0.134 & 0.125 & $\mathbf{0 . 0 2 5}$ & $\mathbf{0 . 0 0 3}$ \\
Haemophilia type & & & & & & & & & & & & \\
A & 92 & & 45.00 & 38.11 & 42.61 & 63.70 & 33.76 & 27.81 & 33.49 & 40.98 & 27.92 & 28.89 & 35.67 \\
B & 26 & & 35.77 & 25.48 & 35.00 & 51.73 & 23.08 & 24.36 & 23.32 & 32.69 & 18.51 & 8.97 & 26.21 \\
& & $P$ (sig.) & 0.076 & $\mathbf{0 . 0 1 5}$ & $\mathbf{0 . 0 9 7}$ & $\mathbf{0 . 0 0 6}$ & $\mathbf{0 . 0 1 4}$ & 0.084 & $\mathbf{0 . 0 0 8}$ & 0.066 & 0.079 & $\mathbf{0 . 0 0 1}$ & $\mathbf{0 . 0 0 1}$ \\
HIV infection & & & & & & & & & & & \\
Yes & 33 & & 49.70 & 41.29 & 48.79 & 72.27 & 40.15 & 25.25 & 34.47 & 45.61 & 37.12 & 37.88 & 40.00 \\
No & 85 & & 40.35 & 33.01 & 37.88 & 56.71 & 28.01 & 27.75 & 30.00 & 36.65 & 21.47 & 19.31 & 31.10 \\
& & $P$ (sig.) & $\mathbf{0 . 0 2 6}$ & 0.086 & $\mathbf{0 . 0 0 9}$ & $<\mathbf{0 . 0 0 1}$ & $\mathbf{0 . 0 0 2}$ & 0.850 & 0.210 & $\mathbf{0 . 0 3 1}$ & $\mathbf{0 . 0 0 2}$ & $\mathbf{0 . 0 0 1}$ & $\mathbf{0 . 0 0 1}$ \\
HCV infection & & & & & & & & & & & \\
Yes & 84 & & 48.63 & 37.50 & 43.39 & 65.06 & 34.90 & 26.29 & 33.11 & 43.10 & 30.21 & 27.28 & 36.45 \\
No & 34 & & 28.97 & 29.96 & 34.85 & 51.18 & 22.79 & 28.92 & 26.65 & 29.41 & 15.07 & 17.65 & 26.52 \\
& & $P$ (sig.) & $\mathbf{0 . 0 0 1}$ & 0.115 & $\mathbf{0 . 0 4 1}$ & $\mathbf{0 . 0 0 1}$ & $\mathbf{0 . 0 0 2}$ & 0.731 & 0.066 & $\mathbf{0 . 0 0 1}$ & $\mathbf{0 . 0 0 1}$ & 0.066 & $\mathbf{0 . 0 0 1}$ \\
\hline
\end{tabular}

PH: physical health, FL: feelings, VW: view, SL: sports/leisure, WS: work/school, DL: dealing, TR: treatment, FU: future, FP: family planning, RP: relationship/partnership, and THQ: total haem-A-QoL. ${ }^{a}$ Analysis was performed using independent samples $t$-test or ANOVA. ${ }^{\mathrm{b}}$ Analysis was performed using Mann-Whitney test or Kruskal-Wallis test.

Scale internal consistency reliability, as expressed by Cronbach's $\alpha$ coefficient, was very high in all dimensions, ranging between 0.765 and 0.954 (Table 2), and exceeded the corresponding reliability coefficients reported in recent similar studies [31,32]. This difference might be attributed to the small sample size of these studies ( $n=30$ and $n=39$, resp.) compared to our sample size $(n=118)$. Only one dimension (dealing) exhibited in our study borderline acceptable reliability (0.585). The two previously mentioned studies using Haem-A-QoL had similar or even worse Cronbach's $\alpha(0.6$ and 0.13 , resp.) in the same Haem-A-QoL dimension $[31,32]$. Test-retest reliability coefficients, measured in $19.5 \%$ of the sample, were likewise considerably high, ranging from 0.872 to 0.974 (Table 2), implying that scale scores were consistent over time from one test administration to the next and that there was little or no influence from external factors.

The hypothesized structure of the Haem-A-QoL was confirmed with evidence provided by item-internal consistency and item-discriminant validity (Table 3 ). Both were satisfactory, suggesting that the translation of the items and the response choices are appropriate and that scale scores derived from the Greek version could contribute to crosscultural comparisons. Criterion-related construct validity was supported by corroboration of hypothesized strong correlations between Haem-A-QoL and SF-36 scales measuring similar dimensions (Table 4).

Multiple stepwise linear regression models exhibited relatively high proportions of HRQoL variance explained. Except for one scale (dealing), all other Haem-A-QoL scales were significant predictors of at least one SF-36 scale, with the dimension "future" contributing to seven and "feelings" to three (Table 5). These findings substantiate that the Greek version of the instrument is indeed measuring standard quality of life aspects.

Known-group comparisons using various demographic and clinical characteristics generated expected results with reference to score variations and the direction of these differences, several of which were also statistically significant, and others were only marginally insignificant. More specifically, age was a significant factor with a negative relationship to perceived health in most Haem-A-QoL scales (Table 6), in accordance with results from adult patients reported elsewhere $[5,6,30,33]$. Other sociodemographic factors, like educational level, employment, and family status, proved to be significant predictors for certain Haem-AQoL subscales, influencing negatively patients' quality of life. Specifically, low educational level was associated in a statistically significant manner with deteriorations in four Haem-A-QoL subscales (physical health, feelings, view, and work/school), as well as in total score (Table 6). Similar findings were reported by another study using Haem-AQoL [19], where patients with low educational level showed significantly more impairment in QoL in the dimensions of feelings, view, treatment, future, and total score. In another study, it is reported that educational level was correlated with the anxiety scale of EQ-5D, but no other correlation was identified with either EQ-5D or SF-36 [30]. The abovementioned demographic features, age and educational level, were also amongst the most pronounced and significant predictors for most of the Haem-A-QoL dimensions, when 
TABLE 8: Multiple stepwise linear regression models.

\begin{tabular}{|c|c|c|c|c|c|c|}
\hline & Predictors & $B$ & SE & $t$ & $P$ value & Adjusted $R^{2}$ \\
\hline \multirow{2}{*}{ Physical health } & (Constant) & 58.05 & 3.991 & 14.546 & $<0.001$ & \multirow{2}{*}{0.146} \\
\hline & $\mathrm{HCV}$ & -9.61 & 2.181 & -4.407 & $<0.001$ & \\
\hline \multirow{2}{*}{ Feelings } & (Constant) & 49.10 & 6.696 & 7.333 & $<0.001$ & \multirow{2}{*}{0.037} \\
\hline & Haemophilia type & -11.68 & 5.154 & -2.266 & 0.025 & \\
\hline \multirow{3}{*}{ View } & (Constant) & 71.82 & 8.883 & 8.085 & $<0.001$ & \multirow{3}{*}{0.090} \\
\hline & HIV & -12.64 & 4.305 & -2.936 & 0.004 & \\
\hline & Prophylaxis & -6.63 & 3.066 & -2.164 & 0.033 & \\
\hline \multirow{4}{*}{ Sports/leisure } & (Constant) & 99.65 & 8.609 & 11.576 & $<0.001$ & \multirow{4}{*}{0.173} \\
\hline & HIV & -10.60 & 4.587 & -2.311 & 0.023 & \\
\hline & $\mathrm{HCV}$ & -5.32 & 2.169 & -2.451 & 0.016 & \\
\hline & Haemophilia type & -9.50 & 4.413 & -2.153 & 0.034 & \\
\hline \multirow{5}{*}{ Work/school } & (Constant) & 57.26 & 8.384 & 6.830 & $<0.001$ & \multirow{5}{*}{0.200} \\
\hline & $\mathrm{HCV}$ & -5.02 & 1.913 & -2.622 & 0.010 & \\
\hline & Prophylaxis & -9.21 & 2.629 & -3.504 & 0.001 & \\
\hline & HIV & -9.48 & 4.019 & -2.359 & 0.020 & \\
\hline & Bleedings & 7.95 & 3.837 & 2.073 & 0.041 & \\
\hline \multirow{2}{*}{ Dealing } & (Constant) & 35.22 & 4.390 & 8.023 & $<0.001$ & \multirow{2}{*}{0.032} \\
\hline & Prophylaxis & -6.50 & 3.049 & -2.131 & 0.035 & \\
\hline \multirow{3}{*}{ Treatment } & (Constant) & 26.51 & 8.239 & 3.217 & 0.002 & \multirow{3}{*}{0.083} \\
\hline & Haemophilia type & -8.66 & 3.693 & -2.345 & 0.021 & \\
\hline & Hematomas & 13.88 & 5.953 & 2.332 & 0.022 & \\
\hline \multirow{4}{*}{ Future } & (Constant) & 44.33 & 8.660 & 5.119 & $<0.001$ & \multirow{4}{*}{0.155} \\
\hline & $\mathrm{HCV}$ & -6.84 & 1.906 & -3.586 & 0.001 & \\
\hline & Prophylaxis & -7.72 & 2.841 & -2.718 & 0.008 & \\
\hline & Hematomas & 14.38 & 6.658 & 2.160 & 0.033 & \\
\hline \multirow{2}{*}{ Family status } & (Constant) & 54.91 & 8.504 & 6.456 & $<0.001$ & \multirow{2}{*}{0.099} \\
\hline & HIV & -16.96 & 4.732 & -3.584 & 0.001 & \\
\hline \multirow{4}{*}{ Relationships/partnership } & (Constant) & 78.54 & 13.191 & 5.954 & $<0.001$ & \multirow{4}{*}{0.132} \\
\hline & Haemophilia type & -13.44 & 6.335 & -2.121 & 0.036 & \\
\hline & HIV & -14.6 & 6.028 & -2.422 & 0.017 & \\
\hline & Prophylaxis & -10.05 & 4.284 & -2.346 & 0.021 & \\
\hline \multirow{4}{*}{ Total Haem-A-QoL } & (Constant) & 55.62 & 4.692 & 11.854 & $<0.001$ & \multirow{4}{*}{0.181} \\
\hline & $\mathrm{HCV}$ & -4.88 & 1.307 & -3.737 & $<0.001$ & \\
\hline & Haemophilia type & -7.42 & 2.856 & -2.598 & 0.011 & \\
\hline & Prophylaxis & -4.23 & 1.964 & -2.155 & 0.033 & \\
\hline \multirow{2}{*}{ Physical health } & (Constant) & 26.31 & 4.608 & 5.710 & $<0.001$ & 0.118 \\
\hline & Age group & 6.81 & 1.678 & 4.058 & $<0.001$ & \\
\hline Feelings & (Constant) & 62.29 & 8.023 & 7.764 & $<0.001$ & 0.086 \\
\hline & Educational level & -11.37 & 3.285 & -3.461 & 0.001 & \\
\hline View & (Constant) & 63.55 & 7.088 & 8.966 & $<0.001$ & 0.078 \\
\hline & Educational level & -9.55 & 2.902 & -3.290 & 0.001 & \\
\hline Sports/leisure & (Constant) & 85.09 & 7.477 & 11.380 & $<0.001$ & 0.079 \\
\hline sports/IElsuie & Educational level & -10.13 & 3.061 & -3.309 & 0.001 & \\
\hline Work/school & (Constant) & 63.50 & 6.392 & 9.935 & $<0.001$ & 0.182 \\
\hline & Educational level & -13.56 & 2.617 & -5.181 & 0.001 & \\
\hline
\end{tabular}


TABLE 8: Continued.

\begin{tabular}{|c|c|c|c|c|c|c|}
\hline & Predictors & $B$ & SE & $t$ & $P$ value & Adjusted $R^{2}$ \\
\hline \multirow{2}{*}{ Dealing } & (Constant) & 19.05 & 4.017 & 4.743 & $<0.001$ & \multirow{2}{*}{0.033} \\
\hline & Age group & 3.26 & 1.463 & 2.225 & 0.028 & \\
\hline \multirow{2}{*}{ Treatment } & (Constant) & 22.95 & 3.526 & 6.510 & $<0.001$ & \multirow{2}{*}{0.050} \\
\hline & Age group & 3.43 & 1.284 & 2.667 & 0.009 & \\
\hline \multirow{2}{*}{ Future } & (Constant) & 54.71 & 7.123 & 7.681 & $<0.001$ & \multirow{2}{*}{0.033} \\
\hline & Educational level & -6.53 & 2.916 & -2.238 & 0.027 & \\
\hline \multirow{3}{*}{ Total Haem-A-QoL } & (Constant) & 40.23 & 6.813 & 5.905 & $<0.001$ & \multirow{3}{*}{0.135} \\
\hline & Educational level & -5.51 & 2.156 & -2.553 & 0.012 & \\
\hline & Age group & 2.63 & 1.123 & 2.338 & 0.021 & \\
\hline
\end{tabular}

$B$ : factor dependence.

SE: standard error.

multiple OLS regression models were performed. Similarly, family status and employment were strongly associated with two (physical health and family planning) and three (physical health, work/school, and total score) Haem-A-QoL scales, respectively (Table 6).

Among the clinical features, severity of the disease, presence of hematoma, and prophylactic treatment were found to have statistically significant correlations with one, two, and four Haem-A-QoL dimensions, respectively (Table 6). More specifically, in our study patients with severe haemophilia had worse quality of life, compared with those suffering from moderate or mild haemophilia. Only the dimension "sports/leisure" was found to be affected by disease severity in a statistically significant manner, which is consistent with another study [32]. However, results concerning severity are contradictory in the literature. Several studies report that severe haemophilia is associated with worse quality of life scores in certain QoL subscales [5, 12, 34-36]. Elsewhere, it is reported that patients with moderate disease demonstrate lower scores in similar or different quality of life subscales than patients with severe haemophilia $[6,36]$. The explanation for this discrepancy given by some authors is that there is a patient selection, in which subjects with moderate disease were more compromised in some respects than those with severe disease [6]. Another possible explanation might be the fact that patients with severe disease might adhere better to treatment therapies in order to overcome their symptoms, whereas patients with moderate or mild haemophilia often exhibit worse treatment adherence and therefore more symptoms.

Prophylaxis, although more expensive than on demand therapy, is currently the preferred treatment strategy, since patients on prophylaxis have less bleeds, are absent fewer days from school or work, spend fewer days in hospitals, and have generally higher QoL. In the present study, only a small percentage (14.4\%) was on constant prophylactic treatment; 9.3\% were on transient prophylaxis; and the majority of the patients $(76.3 \%)$ had no prophylaxis. Patients with no prophylaxis showed higher mean scores (worse quality of life) in the majority of the Haem-A-QoL dimensions, with the most statistically significant ones being physical health, work/school, dealing, and relationship/partnership, compared to patients with transient or constant prophylactic treatment. Similar results were reported by various studies in adults and children [12, 36-39]. Contradictory to this, a study from von Mackensen and Gringeri in Italy reported that patients on prophylactic treatment had worse quality of life compared to those on demand strategy. According to the authors, these conflicting findings could be attributed to the fact that patients in Italy receive prophylactic therapy when they are already in a very severe condition [23].

Viral infections are a common clinical feature amongst haemophilia patients, due to old treatment strategies that employed transfusion of blood products. A high percentage of our sample patients were either HCV or HIV infected (71.2\% and $28.0 \%$, resp.). Hepatitis B virus was present only in two patients of our sample (1.7\%); therefore, its presence was not further studied with regard to HRQoL. As expected, the presence of a viral infection (HCV or HIV) is associated with a continuous decline in self-perceived health in all but one (dealing) Haem-A-QoL dimension (Table 7). Viral infections were identified as significant predictors for seven out of ten Haem-A-QoL subscales and for total score in the regression models (Table 8). Our findings are in accordance with results from numerous previous studies, having reported a negative effect of the presence of either HCV or HIV. Trippoli et al. published substantial worsening of certain QoL subscales, when haemophilia patients had viral infections [6]. Rentz et al, using a patient-reported symptom assessment tool, demonstrated that HIV positive haemophilia patients had more severe symptoms [12]. Lindvall et al. also found that HCV positive haemophilia patients exhibited worse QoL, whereas no differences were identified in HIV positive haemophilia patients [36].

Significant differences in perceived health between the two different types of haemophilia were evident. Patients with haemophilia A exhibited lower mean scores in all Haem-AQoL dimensions compared with patients with haemophilia B. Differences in health were statistically significant in six subscales and in the total score; however, a trend to significance $(P=0.066-0.084)$ could also be detected to the other subscales (Table 7). This finding is consistent 
with recent studies, in which higher bleeding frequency has been observed in patients with haemophilia A compared to patients with haemophilia $B[40,41]$.

Although haemophilia is a rare condition affecting a small percentage of the Greek population (approximately $0.008 \%$ ), costs are disproportionately high and therefore are of elevated economic interest to health care payers. The high cost of recombinant coagulation factors, combined with the fact that haemophilia is often correlated with considerable morbidity and lifelong treatment of the patients, makes this disease a potential target for cost-reducing efforts by health care providers [42, 43]. Hence, QoL assessments could become an integral part of clinical trials, laying the foundation for future economic evaluations in haemophilia, such as cost-utility and cost-effectiveness.

4.1. Limitations of the Study. The study was conducted in only one of the four National Reference Centers of Congenital Bleeding Disorders based in Athens, and one could argue that this restricts the reliability and generalization of results. However, as shown in Table 1, patients visiting this centre come not only from the greater area of Athens (Attica 57.6\%), but also from all over Greece (rest of Greece, 42.4\%), covering a wider geographical distribution and thus compensating for the restriction of the single center. The small sample size $(n=118)$ could explain some of the discrepancies observed during the statistical analysis. Nonetheless, according to the latest national register of haemophilia patients in Greece, it is estimated that approximately 716 adult patients suffer from either haemophilia A or B. Consequently, our sample represents about $16.5 \%$ of the total adult haemophilia patient population, which is adequate enough for a representative study.

\section{Conclusion}

Overall, our findings confirm that the Greek version of Haem-A-QoL is a reasonably good option for measuring health-related quality of life in Greece, filling a current void, and thus contributing to the international literature on the subject. The instrument was well accepted by the patients and proved a reliable and valid tool with psychometric properties similar to those reported in validation studies of the original version and other language versions. The Greek version of Haem-A-QoL can be implemented in the routine assessment of Greek adult patients with haemophilia, since the continuous monitoring of HRQoL parameters can potentially identify specific health care needs of individual patients and verify treatment strategies.

\section{Conflict of Interests}

The authors declare that there is no conflict of interests regarding the publication of this paper.

\section{Acknowledgments}

The authors would like to express their gratitude to Dr. S. von Mackensen and the Haemo-QoL group for granting them permission to use Haem-A-QoL instruments (Greek version), free of charge, for this academic (noncommercial and nonsponsored) study. Finally, the authors are also grateful to the patients who participated in this research.

\section{References}

[1] C. A. Lee, E. Berntorp, and W. K. Hook, Textbook of Hemophilia, Blackwell Publishing, London, UK, 2005.

[2] P. M. Mannucci and E. G. D. Tuddenham, "The hemophiliasfrom royal genes to gene therapy," New England Journal of Medicine, vol. 344, no. 23, pp. 1773-1779, 2001.

[3] P. H. B. Bolton-Maggs and K. J. Pasi, "Haemophilias A and B," The Lancet, vol. 361, no. 9371, pp. 1801-1809, 2003.

[4] World Federation of Hemophilia: Report on the Annual Global Survey 2012, http://wwwl.wfh.org/publications/files/pdf-1574 .pdf.

[5] A. H. Miners, C. A. Sabin, K. H. Tolley, C. Jenkinson, P. Kind, and C. A. Lee, "Assessing health-related quality-of-life in individuals with haemophilia," Haemophilia, vol. 5, no. 6, pp. 378$385,1999$.

[6] S. Trippoli, M. Vaiani, S. Linari, G. Longo, M. Morfini, and A. Messori, "Multivariate analysis of factors influencing quality of life and utility in patients with hemophilia," Haematologica, vol. 86, no. 7, pp. 722-728, 2001.

[7] B. Djulbegovic, G. Goldsmith, D. Vaughn et al., "Comparison of the quality of life between HIV-positive haemophilia patients and HIV-negative haemophilia patients," Haemophilia, vol. 2, no. 3, pp. 166-172, 1996.

[8] S. von Mackensen and M. Bullinger, "Development and testing of an instrument to assess the Quality of Life of Children with Haemophilia in Europe (Haemo-QoL)," Haemophilia, vol. 10, supplement 1, pp. 17-25, 2004.

[9] A. Gringeri, S. von Mackensen, G. Auerswald et al., "Health status and health-related quality of life of children with haemophilia from six West European countries," Haemophilia, vol. 10, supplement 1, pp. 26-33, 2004.

[10] N. L. Young, C. S. Bradley, V. Blanchette et al., "Development of a health-related quality of life measure for boys with haemophilia: the Canadian Haemophilia Outcomes-Kids Life Assessment Tool (CHO-KLAT)," Haemophilia, vol. 10, supplement 1, pp. 34-43, 2004.

[11] M. Manco-Johnson, G. Morrissey-Harding, B. Edelman-Lewis, G. Oster, and P. J. Larson, "Development and validation of a measure of disease-specific quality of life in young children with haemophilia," Haemophilia, vol. 10, no. 1, pp. 34-41, 2004.

[12] A. Rentz, E. Flood, C. Altisent et al., "Cross-cultural development and psychometric evaluation of a patient-reported health-related quality of life questionnaire for adults with haemophilia," Haemophilia, vol. 14, no. 5, pp. 1023-1034, 2008.

[13] P. Arranz, E. Remor, M. Quintana et al., "Development of a new disease-specific quality-of-life questionnaire to adults living with haemophilia," Haemophilia, vol. 10, no. 4, pp. 376-382, 2004.

[14] E. Remor, N. L. Young, S. Von Mackensen, and E. G. Lopatina, "Disease-specific quality-of-life measurement tools for haemophilia patients," Haemophilia, Supplement, vol. 10, supplement 4, pp. 30-34, 2004.

[15] S. von Mackensen, A. Gringeri, and The Haem-A-QoL Study Group, "Development and Pilot Testing of a disease-specific 
quality of life questionnaire for adult patients with haemophilia (Haem-A-QoL)," vol. 104, no. 11, Abstract 2214, 2004.

[16] E. Remor and The Hemolatin-QoL Group, "Hemolatin-QoL: Dessarrollo de unamedidae specificapata la evaluancion de la calidad de vida en pacientes adultos con hemophilia en America-Latina: el Hemolatin-QoL," Revista Interamericana de Psicologia, vol. 39, pp. 211-220, 2005.

[17] A. Gringeri and S. Von Mackensen, "Quality of life in haemophilia," Haemophilia, vol. 14, supplement 3, pp. 19-25, 2008.

[18] S. von Mackensen, A. Gringeri, S. Ravera et al., "Validation of the haemophilia-specific quality of life questionnaire for adult patients with haemophilia (Haem-A-QoL)," Haematologica, vol. 20, supplement 2, abstract 0290, pp. 115-116, 2005.

[19] S. von Mackensen, L. Scalone, S. Ravera, L. Mantovanni, and A. Gringeri, "Assessment of health-related quality of life in patients with haemophilia with the newly developed haemophiliaspecific instrument Haem-A-QoL," Value in Health, vol. 8, no. 6, Abstract PHM5, p. A127, 2005.

[20] S. von Mackensen, M. Strandberg-Larsen, and S. Celerier, "Linguistic validation of haemophilia-specific patient-related outcomes (Haemo-QoL, Haem-A-QoL, Haemo-Sat) in up to 32 languages," Value in Health, vol. 12, no. 7, p. A383, 2009.

[21] L. Chevallet, J. H. Weatherall, and S. von Mackensen, "Linguistic validation of the Haemo-QoL and Haem-A-QoL for use in international studies," Value in Health, vol. 11, no. 3, p. A165, 2008.

[22] M. Bullinger, D. Globe, J. Wasserman, N. L. Young, and S. Von MacKensen, "Challenges of patient-reported outcome assessment ih Hemophilia Care-a State of the Art Review," Value in Health, vol. 12, no. 5, pp. 808-820, 2009.

[23] S. von Mackensen and A. Gringeri, "Quality of life in Haemophilia," in Handbook of Disease Burdens and Quality of Life, pp. 1895-1920, Springer, Heidelberg, Germany, 2009.

[24] Haemo-QoL Group, Scoring Manual, http://www.haemoqol.de/.

[25] J. E. Ware Jr. and C. D. Sherbourne, "The MOS 36-item shortform health survey (SF-36). I. Conceptual framework and item selection," Medical Care, vol. 30, no. 6, pp. 473-483, 1992.

[26] E. Pappa, N. Kontodimopoulos, and D. Niakas, "Validating and norming of the Greek SF-36 Health Survey," Quality of Life Research, vol. 14, no. 5, pp. 1433-1438, 2005.

[27] J. C. Nunnaly and I. R. Bernstein, Psychometric Theory, McGraw-Hill, New York, NY, USA, 1994.

[28] J. Cohen, “A power primer," Psychological Bulletin, vol. 112, no. 1, pp. 155-159, 1992.

[29] N. Kontodimopoulos and D. Niakas, "Determining the basic psychometric properties of the Greek KDQOL-SFUं," Quality of Life Research, vol. 14, no. 8, pp. 1967-1975, 2005.

[30] V. Papagiannopoulou, J. Pittadaki, P. Peristeris, E. Pokas, and J. Yfantopoulos, "Health-related quality of life of people with haemophilia in Greece," Archives of Hellenic Medicine, vol. 24, supplement 1, pp. 85-92, 2007.

[31] A. Mercan, N. Sarper, M. Nanir et al., "Hemophilia-specific quality of life index (Haemo-QoL and Haem-A-QoL Questionnaires) of children and adults: result of a single center from Turkey," Pediatric Hematology and Oncology, vol. 27, no. 6, pp. 449-461, 2010.

[32] A. A. Ferreira, I. C. Leite, M. T. Bustamante-Teixeira et al., "Health-related quality of life in hemophilia: results of the Hemophilia-Specific Quality of Life Index (Haem-a-QoL) at a Brazilian blood center," Revista Brasileira de Hematologia e Hemoterapia, vol. 35, no. 5, pp. 314-318, 2013.
[33] P. Molho, N. Rolland, T. Lebrun et al., "Epidemiological survey of the orthopaedic status of severe haemophilia A and B patients in France," Haemophilia, vol. 6, no. 1, pp. 23-32, 2000.

[34] S. Solovieva, "Clinical severity of disease, functional disability and health-related quality of life. Three-year follow-up study of 150 Finnish patients with coagulation disorders," Haemophilia, vol. 7, no. 1, pp. 53-63, 2001.

[35] J. A. Aznar, M. Magallón, F. Querol, E. Gorina, and J. M. Tusell, "The orthopaedic status of severe haemophiliacs in Spain," Haemophilia, vol. 6, no. 3, pp. 170-176, 2000.

[36] K. Lindvall, S. Von Mackensen, and E. Berntorp, "Quality of life in adult patients with haemophilia-a single centre experience from Sweden," Haemophilia, vol. 18, no. 4, pp. 527-531, 2012.

[37] S. Royal, W. Schramm, E. Berntorp et al., "Quality-of-life differences between prophylactic and on-demand factor replacement therapy in European haemophilia patients," Haemophilia, vol. 8, no. 1, pp. 44-50, 2002.

[38] R. J. Liesner, K. Khair, and I. M. Hann, “The impact of prophylactic treatment on children with severe haemophilia," British Journal of Haematology, vol. 92, no. 4, pp. 973-978, 1996.

[39] K. Fischer, J. Astermark, J. G. Van Der Bom et al., "Prophylacticc treatment for severe haemophilia: comparison of an intermediate-dose to a high-dose regimen," Haemophilia, vol. 8, no. 6, pp. 753-760, 2002.

[40] K. Nagel, I. Walker, K. Decker, A. K. C. Chan, and M. K. Pai, "Comparing bleed frequency and factor concentrate use between haemophilia A and B patients," Haemophilia, vol. 17, no. 6, pp. 872-874, 2011.

[41] G. D. O. Lowe and C. A. Ludlam, "Less severe bleeding in hemophilia B than in hemophilia A," Journal of Thrombosis and Haemostasis, vol. 6, no. 11, pp. 1982-1983, 2008.

[42] M. A. Escobar, "Health economics in haemophilia: a review from the clinician's perspective," Haemophilia, vol. 16, supplement 3, pp. 29-34, 2010.

[43] K. A. Johnson and Z.-Y. Zhou, "Costs of care in hemophilia and possible implications of health care reform," Hematology/American Society of Hematology. Education Program, vol. 1, pp. 413-418, 2011. 


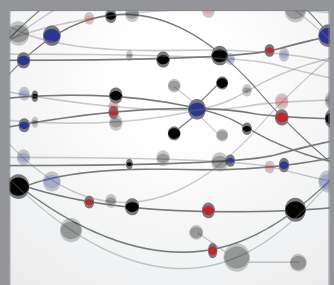

The Scientific World Journal
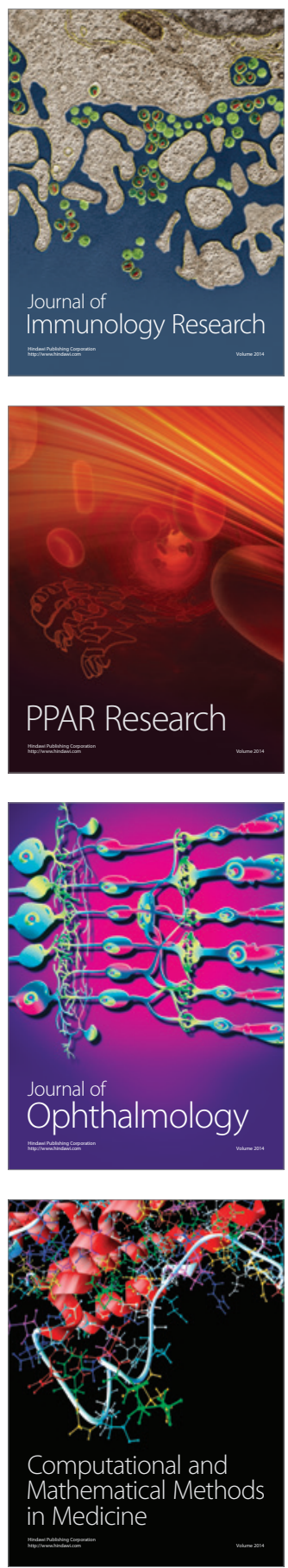

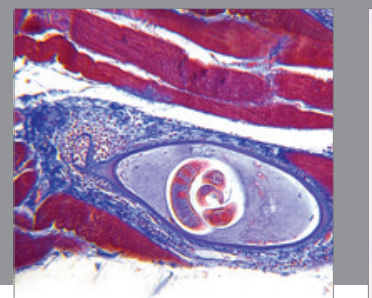

Gastroenterology

Research and Practice
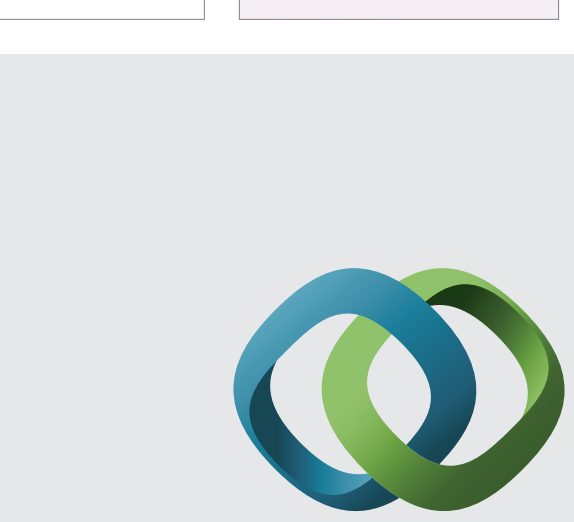

\section{Hindawi}

Submit your manuscripts at

http://www.hindawi.com
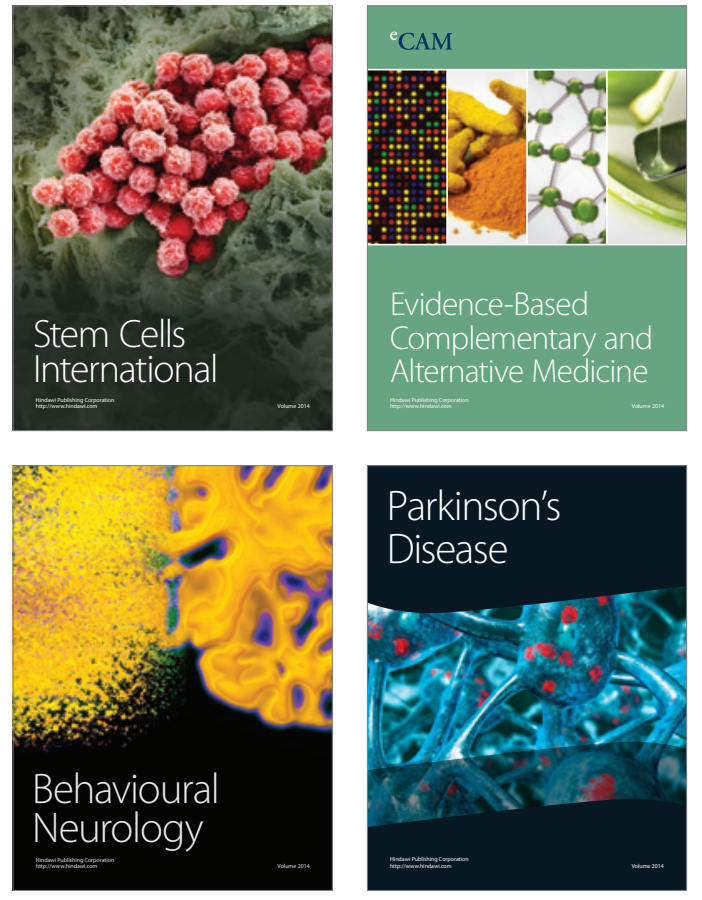
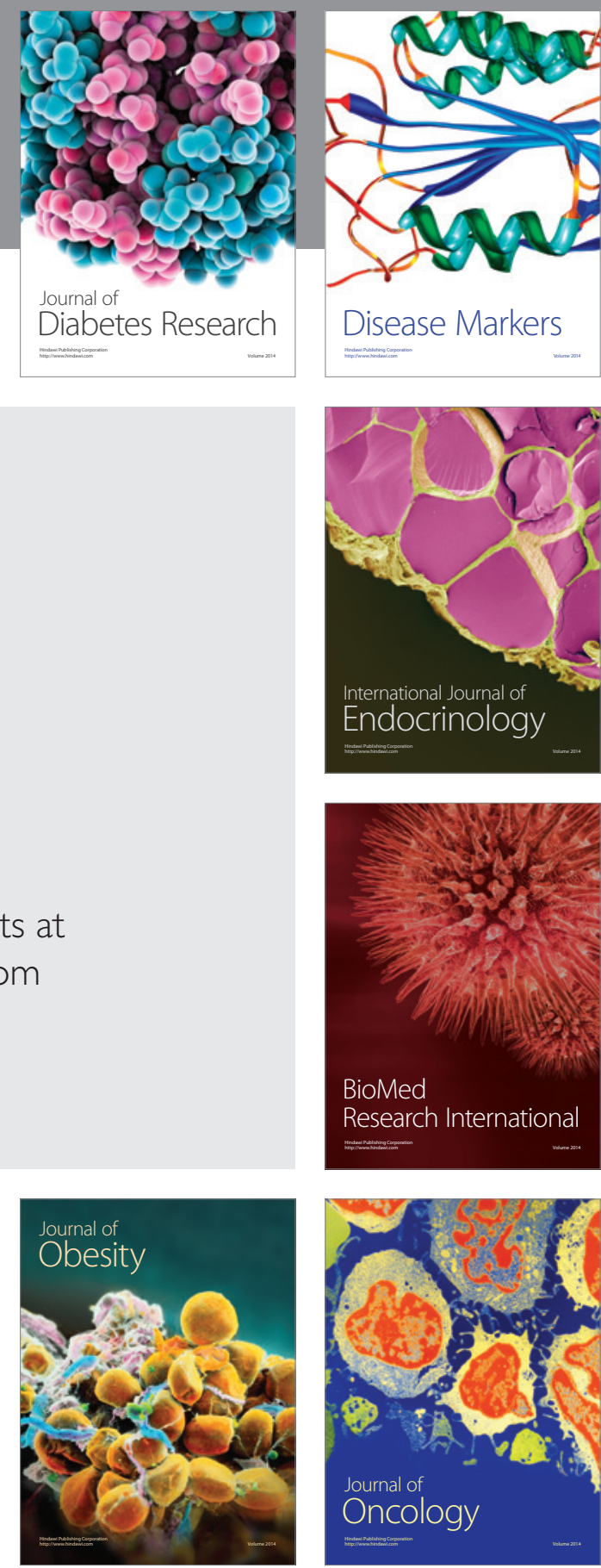

Disease Markers
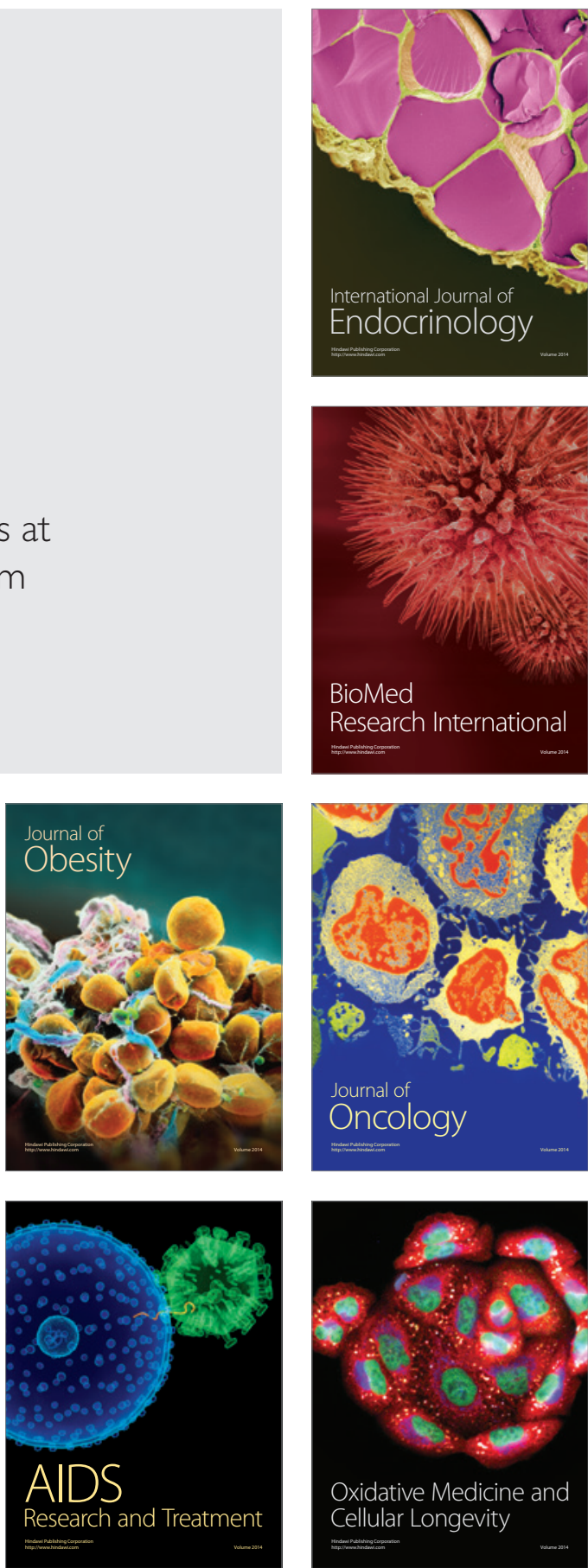